\title{
Neutral or Framed? A Sentiment Analysis of 2019 Abortion Laws
}

\author{
Danny Valdez ${ }^{1}\left[\right.$ Patricia Goodson ${ }^{2}$
}

Accepted: 7 January 2022 / Published online: 18 January 2022

( ) The Author(s), under exclusive licence to Springer Science+Business Media, LLC, part of Springer Nature 2022

\begin{abstract}
Introduction This study employs sentiment analysis (SA) to examine the semantic structures of restrictive and protective abortion bills enacted in 2019. SA is a Natural Language Processing (NLP) technique that uses automation to extract affective indicators (emotive language) from text data. Assessing these indicators can help identify whether legal texts are framed, or intentionally biased in their wording. Identifying framing is important for understanding potentially biased interpretations of these laws.

Methods We identified a sample of 2019 abortion bills using the legislative tracking tool Legiscan and included those that met specified criteria ( $N=19$ bills). We categorized each bill as restrictive $(n=12)$ or protective $(n=7)$. We ran aggregate (i.e., all bills) and separate (protective $\times$ restrictive) SA, generating scores that we interpreted qualitatively (higher scores indicated predominance of positive wording).

Results In the aggregate analysis, $56 \%$ of text comprised negative terms (44\% positive). Restrictive bills contained more negative language than protective bills $(67 \%$ vs $58 \%)$. Although SA scores varied from -222 to +13 , two laws scored 0 , indicating neutrality. For comparison, the US Constitution's score equaled 1.

Conclusion Our findings confirm SA is useful to examine legal documents for language biases. The abortion bills we assessed seem framed along political ideologies, although the sample provided evidence that neutral wording is possible.

Policy Implications With the recent additions of conservative-leaning Justices to the US Supreme Court, Roe v. Wade is again at the center of partisan conflict. Thus, how abortion laws are framed draws further implications for how they may be interpreted when challenged in the court system.
\end{abstract}

Keywords Abortion $\cdot$ Law $\cdot$ Sentiment analysis $\cdot$ Natural Language Processing $\cdot$ SCOTUS

\section{Introduction}

Conventional wisdom argues that within the highest legal court in the USA, judicial impartiality should be unaffected by the addition of new judges to the panel (Gibson \& Nelson, 2014). However, the recent appointments of conservative Justices Brett Kavanaugh (appointed in 2018) and Amy Coney Barrett (appointed in 2020) have raised questions among reproductive rights advocates about the ability of the Supreme Court of the United States (SCOTUS) to retain an impartial

Danny Valdez

danvald@iu.edu

1 Department of Applied Health Science, Indiana University School of Public Health, 1025 E 7th St \#111, Bloomington, IN 47405, USA

2 Department of Health \& Kinesiology, Texas A\&M University, 2929 Research Parkway, College Station, TX 77845, USA stance on the abortion issue. During these Justices' confirmation hearings, many politicians, the media, and the public expressed concerns over the possibility that Roe v. Wade (the case that legalized abortion in the USA) could face challenges and possible revocation (Litman, 2020). An ideologically conservative-leaning SCOTUS could motivate or facilitate these challenges and possibly revoke the law if impartiality is not maintained.

Yet, a person's impartiality on a given issue can be influenced — both consciously and sub-consciously — by the information and messages that person consumes (Feick et al., 2021; Gambrill \& Reiman, 2011; Oliver et al., 2019). In particular, how such information and messages are framed seems to have significant effects on people's attitudes, beliefs, choices, and evaluative judgements.

The term framing refers to a process of shaping the information or messages being communicated within social groups by specifically appealing to the most salient or important aspects of people's beliefs (Tannen, 1993). 
Psychologists who study how opinions, judgments, and beliefs are formed claim that people harbor in their cognitive schemas a set of dimensions that are invoked when a person is judging an issue (when choosing, deciding, or voting, for example (see Druckman, 2004).

This set of dimensions forms a person's "frame of thought" (Chong \& Druckman, 2007, p.105). For example, regarding abortion, a person may invoke beliefs from the dimensions of religion, economics, and psychology to form an opinion about the practice. These dimensions may be equally salient or share the same level of importance for one person, whereas for others, one dimension can "dominate all other considerations" when making a judgement or evaluating an issue. In the case of abortion, a person's religious beliefs, for instance, may constitute one such dimension that transcends other considerations when forming an opinion on the matter. By contrast, a person's valuing of reproductive autonomy may likewise transcend other considerations, including religion, when forming an opinion.

Communicators of all stripes, but particularly those crafting authoritative documents such as legislation or policies, understand how choosing to address or emphasize the most salient/important dimensions related to a given topic can influence how people's ultimate opinions about that topic take shape (i.e., what is also known as "frames in communication" - Chong \& Druckman, 2007, p. 106). Moreover, communicators understand the value of expression using language that reflects those dimensions. Specifically, the authors of legislation and policies make use of select words and phrases to frame an issue by emphasizing some of its dimensions and neglecting (or minimizing) others. For example, if matters related to abortion are presented by repeated use of words such as "rights," "health," or "choice," then the text appeals to listeners' human rights frame of thought. If abortion topics are presented with text that emphasizes words such as "unborn," "death," or "murder," the frame being invoked is one of law-breaking or crime.

According to Chong and Druckman (2007), "how frames in the communications of elites (e.g., politicians, media outlets, interest groups) influence citizens' frames and attitudes" (p. 109) is known as a "framing effect." Identifying how abortion-related legislation is framed is an important step in understanding any framing effects that might ensue, including potentially biased interpretations of those laws.

In this paper we explore the potential framing of abortion bills and associated laws within each bill proposed and/or enacted in 2019. We report an assessment of the texts of these bills to answer two specific questions related to their wording:
1. How do these bills' written texts fare when mapped using sentiment analysis (i.e., the degree of positivity and negativity in each bill)?

2. How does the framing of these bills compare against the US Constitution - the seminal US doctrine to which most laws are compared?

We note this study is grounded upon the assumption that legal documents should be worded in neutral terms and intentionally crafted to facilitate impartiality. Because framing in communication can significantly shape an audience's attitudes and beliefs, framing can have serious implications for a society's governance and political systems, its communication processes, and its education efforts. Put simply, framing is important because it can have both positive and negative - but rarely trivial - effects in the "operation of a democratic political system" (Chong \& Druckman, 2007, p. 104).

\section{Methods}

\section{Design}

Sentiment Analysis Sentiment analysis (SA) refers to one of many Natural Language Processing (NLP) techniques that use automation to read and extract indicators from text. As with other NLP methodologies, which include topic modeling (Blei et al., 2003) and machine learning classification (Kotsiantis, 2007), the theoretical suppositions of this class of methods argue that words can, themselves, be treated and studied as individual datapoints. When analyzed via algorithms, these words can be further leveraged to draw inferences about the collection of words, themselves, or generalized outward to other human phenomena (Valdez \& Goodson, 2020).

As an analytic tool, sentiment analysis is used to study latent emotions within words and how those words may predict and/ or infer human emotion (Feldman, 2013). To identify these latent emotions, the automated tool "reads" the text submitted for analysis (such as social media posts, book chapters, or any logically structured collection of words) and compares these words to a built-in lexicon or dictionary. This dictionary is pre-programmed to identify emotionally charged words in the English language that contain positive (i.e., affirmative, supportive) and/or negative (i.e., dismissive, pessimistic) connotations. Each of the various sentiment analysis algorithms will use a unique, often proprietary, lexicon to identify and quantify emotionally charged words. However, most are constructed through a similar process using several human raters 
to ascribe positive, negative, or neutral values to all words in the English language. These individual coding exercises are then compared and/or corrected for reliability and program validation purposes before the algorithm is available for public use (see Hutto \& Gilbert, 2014 for an example of how a lexicon is constructed).

Within the social sciences, sentiment analysis has been applied in psychology and public health contexts to study individuals' and population's moods. For example, Bathina et al. (2021) found that individuals who self-disclosed a depression diagnosis on social media were more likely to exhibit decreased sentiment, or worse mood, and distorted writing patterns on their personal feeds. At the population level, Valdez et al. (2020) similarly found sentiment of a random cohort of social media users declined throughout 2020, primarily attributed to the ongoing effects of the COVID-19 pandemic, among other co-occurring natural events. Beyond mood, researchers have extensively leveraged sentiment analysis to study latent opinion by analyzing product reviews (Mukherjee \& Bhattacharyya, 2012) among other content posted by Internet users (Cao et al., 2014).

Although researchers have recommended applying machine learning and NLP to study legal texts (Lehr \& Ohm, 2017), as far as we can determine, no studies have applied sentiment analysis, specifically, to bills and policies on abortion (Pozen et al., 2019). This study represents, therefore, an initial empirical effort to assess the sentimentality framing of legal texts in the USA, by focusing on a corpus of abortion bills proposed and enacted in 2019.

\section{Data Collection}

The year following Brett Kavanaugh's confirmation to the SCOTUS (i.e., 2019), legislators in 26 states enacted hundreds of laws regarding abortion (see Nash, 2019). Many of these laws were couched into comprehensive, state-level bills that overhauled, to varying extents, existing abortion laws. It is important to note that because these comprehensive bills may comprise dozens, if not hundreds, of laws regarding various issues, it is difficult to ascertain the exact number of laws related to abortion that were motioned in 2019. However, groups such as the Guttmacher Institute compile comprehensive estimates and aggregated statistics on these bills (see https://www.guttmacher.org/article/ 2019/12/state-policy-trends-2019-wave-abortion-bans-somestates-are-fighting-back).

Given abortion has long been considered a divisive political and social issue McKeegan (1993), the 2019 state abortion bills varied considerably regarding scope and content. Nonetheless, a useful distinction is the one made by the Guttmacher Institute, which broadly classifies these bills/laws as (a) abortionprotection laws - those amending or enacting protections for legal access to abortion or women seeking abortions, alongside expanding "access to contraceptive services and sex education" or (b) abortion-restriction laws - regulations inhibiting or curbing access to legal abortions (https://www.guttmacher.org/ article/2019/12/state-policy-trends-2019-wave-abortion-banssome-states-are-fighting-back).

We identified and downloaded the complete texts of 19 state abortion bills and their accompanying laws, which formed the final corpus for our analyses. We had initially examined over 50 individual laws (several per state), but quickly realized that because each bill bundled many laws, it proved more efficient to select comprehensive bills (and the laws they carried), than to select individual laws. We selected the 19 bills in our sample, based on four criteria. First, each of these 19 bills was motioned after Justice Brett Kavanaugh's confirmation to the US Supreme Court - largely signaling the beginning of legislative/judicial attempts to repeal Roe v. Wade; second, these bills were enacted into law; third, many were contested by the public, and fourth and most importantly, these bills drew heavy attention (e.g., fetal heartbeat laws) on major media outlets - both in the context of outlawing abortion or protecting access to it (https:// www.usnews.com/news/best-states/articles/a-guide-toabortion-laws-by-state).

To collect the full text of each bill, we used Legiscan. Legiscan is a non-partisan legislative tracking and Application Programming Interface (API) used to provide structured JavaScript Object Notification (JSON) streams including detailed bill information such as its history, full text, sponsor, roll call, votes, and associated meta data such as previous versions of each bill. Any user can access the Legiscan API, which offers a user-friendly interface to search, read, and download copies of most bills/laws, barring certain restrictions such as redactions in classified bills (see: https://legiscan.com/).

As we downloaded each bill, we attempted to collate all laws within each bill. Georgia's HB481, for example, contained at least two dozen individual laws and mandates embedded within it, which targeted different facets of abortion such as barring abortion if a fetal heartbeat can be detected, or mandating attending physicians to offer sonograms prior to the abortion procedure. After obtaining access to the laws' text, two raters unaffiliated with this study, but experts in abortion science, reviewed each bill to determine if it upheld abortion rights (protective laws) or limited abortion access (restrictive laws). The raters then cross-checked the bills with the Guttmacher Institute's classification of each bill. Upon completing the review, 7 of the 19 bills were designated as abortion protective, and 12 were abortion restrictive (Table 1). 
Table 1 Selected list of 2019 enacted abortion laws

\begin{tabular}{llll}
\hline State & Bill & Common name/purpose & Classification \\
\hline Alabama & HB314 & The Human Life Protection Act & Restrictive \\
Arkansas & HB1439 & The Cherish Act & Restrictive \\
Georgia & HB481 & The Living Infants Fairness and Equality (LIFE) Act & Restrictive \\
Illinois & SB25 & Reproductive Health Act & Protective \\
Indiana & HB1211 & The 'Dismemberment Abortion' Ban Act & Restrictive \\
Kentucky & SB9 & An Act Relating to Abortion and Declaring an Emergency & Restrictive \\
Louisiana & SB184 & Prohibits the Abortion of an Unborn Human Being with a Detectable Heartbeat & Restrictive \\
Maine & HP922 & Act to Authorize Certain Healthcare Professionals to Perform Abortions & Protective \\
Massachusetts & SB1209 & Act to Remove Obstacles and Expand (ROE) Abortion Access & Restrictive \\
Mississippi & HB1510 & Gestational Age Act & Restrictive \\
Missouri & HB126 & Missouri Stands for the Unborn Act & Protective \\
Nevada & SB127 & Trust Nevada Women Act & Protective \\
New York & S2796 & Reproductive Health Act & Restrictive \\
North Dakota & HB1546 & An Act Relating to the Prohibition on Human Dismemberment Abortion & Restrictive \\
Ohio & SB23 & Prohibit Abortion if Detectable Heartbeat Act & Protective \\
Rhode Island & H5125 & Reproductive Privacy Act & Restrictive \\
Tennessee & HB0077 & Prohibits Abortions from the Point a Fetal Heartbeat is Detected & Restrictive \\
Utah & HB136 & Abortion Amendments & Protective \\
Vermont & H57 & Act Relating to Preserving the Right to Abortion &
\end{tabular}

\section{Procedure}

Because our research questions are exploratory in nature, we opted for a simple sentiment analysis with a ratio-derived sentiment score. The calculus for this type of sentiment analysis algorithm reads each bill, compares the text against the lexicon, and tallies the number of positive and negative words in each bill. Negative words receive a score of -1 , and positive words receive $a+1$ score. These numbers are added to provide a sum sentiment score. For example, in the phrase "I support a their right to choose," the words support, right, and choose would each carry a score of +1 , for a sentiment score of +3 . By contrast, in the phrase, "abortion is murder of an unborn child," the words abortion, murder, and unborn would each carry a score of -1 for a composite sentiment score of -3 . For the phrase, "Abortion is wrong, but I support a someone's right to reproductive autonomy," the words abortion and wrong would score -1 each, and support, right, and autonomy would score +1 for a composite score of +1 . Intuitively, higher scores denote greater sentiment, or more positive affect; lower scores denote lower sentiment, or more negative affect.

Data Processing To prepare the data for sentiment analysis, we extracted each bill's text, saved the text as a .txt file, and saved the file into either an abortion protective or abortion restrictive folder. To inform the computer that words were to be treated as datapoints, we created a document-term-matrix (DTM) from all .txt files. A DTM represents an aggregate count of each word used in the bills. However, a DTM will not contain words that provide no semantic value, such as articles (a, and, the), and prepositions (with, to, in, on, for example). Of note, the DTM is derived through automation, which means the computer program removes these non-semantically valuable words automatically. After generating a DTM, we reviewed the file to ensure no words with semantic value were erroneously removed.

Data Analysis We then ran a series of sentiment analyses for this study using the "Sentiment Analysis" package in R 3.6.2 (Procellochs \& Feuerriegel, 2021). For more information about the coding process used to create the lexicon, please refer to https://cran.r-project.org/web/packages/ SentimentAnalysis/SentimentAnalysis.pdf.

First, we ran a general sentiment analysis employing all laws combined, not accounting for their category (protective or restrictive). We used this analysis to determine the general frequency of words, and degree of positivity/negativity in the aggregate collection of bills. We then analyzed the abortion protective and restrictive bills, separately, to identify differences and similarities in sentimentality (i.e., Was one group of bills more positive/negative than the other?). Subsequently, we reviewed each bill against our output to determine if any words were erroneously coded as having positive, negative, or neutral affect. For example, the word "vice" was coded negatively. However, because "vice," in the bills' text, referred to "Vice President" and not "personal 
vices," we removed "vice" from consideration and re-ran our analyses.

In most NLP studies, neutral reference points are used as "null-models" established as reference for the analyses. To establish a neutral reference point, and to ground our study in a null-model, we conducted a sentiment analysis of the US Constitution, the foundation of the American legal system. We selected the US Constitution (controversies of exclusive language notwithstanding) for several reasons. First, the US Constitution serves as a governing doctrine to which most bills and laws are compared in the judiciary. Second, when laws are challenged in the court system, they are inevitably weighed by their constitutionality, a process that relies heavily on analyses of the wording of the text.

\section{Results}

\section{General Sentiment Analysis}

We identified 6452 emotionally charged words in the abortion bills corpus: $\mathrm{DTM}_{\text {Protective }}(n=3041)$ and $\mathrm{DTM}_{\text {Restrictive }}$ $(n=3441)$. The general analysis (i.e., all texts analyzed in tandem) yielded a total sentiment score of -1011 or $56 \%$ negativity, and $44 \%$ positivity. Stated differently, when the words of all texts were combined, $56 \%$ of the words comprised negative terms and $44 \%$, positive. Table 2 illustrates the top ten most used negative and positive words in the combined dataset, as determined by their frequency/count in the texts.

\section{Comparative Sentiment Analyses: Protective vs. Restrictive Laws}

We next performed distinct sentiment analyses for the abortion protective and abortion restrictive bills. Abortion restrictive laws contained more negative language than abortion protective laws: $68 \%$ negative, among the restrictive group, and 50\% negative in the protective group (Table 3 ). The majority of the restrictive bills (11 of 12) had negative sentiment scores, while 3 of the 7 protective bills also exhibited overall negative scores (Illinois SB25, New York S2796, and Rhode Island H5125). Two bills, Georgia's HB481 and Vermont's H57, scored 0 , indicating an equal use of negative and positive words, or neutrality.

Table 4 highlights the top ten most used positive and negative words within both sets of abortion bills. Commonalities among the bills include the words "violation" and "failure" as highly used negative words, and "available," "appropriate," and "right" as highly used positive words. Words used uniquely by each group included "pain," "subpoena," "death," "unconstitutional," "qualified," and "covenant" utilized by the restrictive laws, and "waste," "abuse,"
Table 2 Most frequently used positive and negative words for all combined bills in the general sentiment analysis. These words were first identified in the DTM, then assigned Negative/Positive Value through the sentiment analysis algorithm. Please note that while abortion was the most-used negative word overall, we did not include that information in this table. This is due to the term abortion accounting for a majority of total negative terms used in the corpus

Combined bills

\begin{tabular}{lllll}
\hline Negative & & & Positive & \\
\cline { 1 - 2 } \cline { 5 - 5 } Word & $\begin{array}{l}\text { Frequency/ } \\
\text { Count }\end{array}$ & & Word & $\begin{array}{l}\text { Frequency/ } \\
\text { Count }\end{array}$ \\
\hline Violation & 150 & & Available & 74 \\
Death & 127 & & Reasonable & 63 \\
Guilty & 94 & & Effective & 52 \\
Emergency & 89 & & Right & 50 \\
Criminal & 73 & & Appropriate & 43 \\
Limited & 73 & & Advanced & 40 \\
Failure & 64 & & Benefits & 34 \\
Risk & 51 & & Respect & 25 \\
Injury & 38 & & Supreme & 25 \\
Abuse & 35 & Best & 23 \\
\hline
\end{tabular}

"neglect," "advanced," "benefits," "respect," and "effective" for protective laws.

\section{Comparing Sentiment Analysis Scores: Abortion Bills vs US Constitution}

To contrast our findings with a null-model (in keeping with the standard procedures in NLP analyses), we conducted a sentiment analysis of the US Constitution, including the Bill of Rights and 27 subsequent amendments. We followed the same procedure described above to isolate words with semantic value and remove redundant articles and prepositions. When compared to the US Constitution sentiment analysis score of 1 , most bills in both categories in our sample (protective and restrictive) contained a large amount of both positive and negative terms: bills range in sentimentality scores from -222 to 0 (restrictive) and -175 to 13 (protective). Only two bills (Georgia HB481 and Vermont H57) scored neutrally (zero).

\section{Discussion}

The purpose of this study was to identify how a set of abortion bills proposed and/or enacted in 2019 fared, regarding the use of positive or negative sentiment language in their texts. We selected 2019 abortion laws specifically given that during the time of writing, this bulk of legislation represented the beginning of renewed attempts to challenge Roe v. Wade amid an ideologically imbalanced SCOTUS. Our principal finding indicated that, collectively, enacted bills were only 
Table 3 Sentiment scores per each protective and restrictive law, including the percent of positive and negative words within each bill. Please note we chose to keep "abortion" in our corpus despite the

Abortion restrictive laws

\begin{tabular}{|c|c|c|c|c|c|c|c|c|c|c|c|}
\hline \multirow[t]{2}{*}{ State } & \multirow{2}{*}{$\begin{array}{l}\text { Total negative } \\
\text { words }\end{array}$} & \multirow{2}{*}{$\begin{array}{l}\text { Total positive } \\
\text { words }\end{array}$} & \multirow{2}{*}{$\begin{array}{l}\text { Sentiment } \\
\text { Scores }\end{array}$} & \multirow{2}{*}{$\begin{array}{l}\% \\
\mathrm{Neg}\end{array}$} & \multirow{2}{*}{$\begin{array}{l}\% \\
\text { Pos }\end{array}$} & \multirow[t]{2}{*}{ State } & \multirow{2}{*}{$\begin{array}{l}\text { Total negative } \\
\text { words }\end{array}$} & \multirow{2}{*}{$\begin{array}{l}\text { Total positive } \\
\text { words }\end{array}$} & \multirow{2}{*}{$\begin{array}{l}\text { Sentiment } \\
\text { Scores }\end{array}$} & \multirow{2}{*}{$\begin{array}{l}\% \\
\text { Neg }\end{array}$} & \multirow{2}{*}{$\begin{array}{l}\% \\
\text { Pos }\end{array}$} \\
\hline & & & & & & & & & & & \\
\hline Kentucky & 272 & 50 & -222 & 84 & 16 & Illinois & 617 & 442 & -175 & 58 & 42 \\
\hline Ohio & 369 & 178 & -191 & 67 & 33 & Rhode Island & 153 & 68 & -85 & 69 & 31 \\
\hline Missouri & 339 & 224 & -115 & 60 & 40 & New York & 98 & 28 & -70 & 78 & 22 \\
\hline Mississippi & 74 & 29 & -45 & 72 & 28 & Vermont & 19 & 19 & $\mathbf{0}$ & 50 & 50 \\
\hline Utah & 41 & 8 & -33 & 84 & 16 & Massachusetts & 7 & 17 & 10 & 29 & 71 \\
\hline Alabama & 52 & 22 & -30 & 70 & 30 & Maine & 18 & 28 & 10 & 39 & 61 \\
\hline Indiana & 66 & 39 & -27 & 63 & 37 & Nevada & 8 & 21 & 13 & 28 & 72 \\
\hline Arkansas & 55 & 34 & -21 & 62 & 38 & & & & & & \\
\hline Tennessee & 23 & 5 & -18 & 82 & 18 & & & & & & \\
\hline Louisiana & 27 & 15 & -12 & 64 & 36 & & & & & & \\
\hline North Dakota & 15 & 11 & -4 & 58 & 42 & & & & & & \\
\hline Georgia & 83 & 83 & $\mathbf{0}$ & 50 & 50 & & & & & & \\
\hline Mean & 118 & 58 & -59 & 68 & 32 & Mean & 131 & 89 & -42 & 50 & 50 \\
\hline
\end{tabular}

marginally negative (56\%). However, when disaggregated, all abortion restrictive laws contained more negative-leaning language than positive-leaning language - as reflected in their total sentiment scores.

Even though these findings might not be surprising, they bare meaningful implications deserving discussion, namely, (a) the adequacy of SA as a polarization analysis tool, (b) the context(s) within which restrictive and protective laws are framed, and (c) possible outcomes of semantically framed legislation guiding complex and polarized social issues.

\section{SA as a Polarization Analysis Tool}

Our findings support the notion that legal documents represent appropriate data units for sentiment analysis. In our term inflating negative sentiment scores. This may partially explain why several of the abortion protection laws received such high sentiment scores
Abortion protective laws

words words

study, sentiment analysis was able to identify differences in the degree of negativity/positivity among the various bills, alongside patterns within each category. While in both categories (protective and restrictive) sentiment analysis identified at least one bill exhibiting a score of 0 (or perfect neutrality), restrictive bills were notably more negative in their wording than protective bills, while the majority of protective bills contained more positive language.

As demonstrated in our study, sentiment analysis as an analytical tool can be useful to diagnose polarization of legal documents, alongside the extent to which the documents' texts skew positively or negatively. Nonetheless, as with all NLP analyses, additional context is needed to interpret these outcomes and associated implications (Valdez et al., 2021).
Table 4 Most frequently used positive and negative words by group. Please note that while abortion was the most-used negative word overall, we did not include that information in this table. This is due to the term abortion accounting for a majority of total negative terms used in the corpus

\begin{tabular}{|c|c|c|c|c|c|c|c|}
\hline \multicolumn{4}{|c|}{ Protective abortion bills } & \multicolumn{4}{|c|}{ Restrictive abortion bills } \\
\hline \multicolumn{2}{|l|}{ Negative } & \multicolumn{2}{|l|}{ Positive } & \multicolumn{2}{|l|}{ Negative } & \multicolumn{2}{|l|}{ Positive } \\
\hline Word & Count & Word & Count & Word & Count & Word & Count \\
\hline Guilty & 88 & Available & 22 & Criminal & 56 & Advanced & 33 \\
\hline Violation & 77 & Supreme & 17 & Death & 56 & Available & 25 \\
\hline Failure & 41 & Qualified & 13 & Limited & 33 & Appropriate & 18 \\
\hline Pain & 27 & Appropriate & 12 & Waste & 33 & Benefits & 18 \\
\hline Emergency & 25 & Reasonable & 8 & Abuse & 24 & Respect & 17 \\
\hline Limited & 15 & Right & 9 & Violation & 19 & Effective & 15 \\
\hline Risk & 15 & Well & 9 & Neglect & 17 & Reasonable & 14 \\
\hline Subpoena & 15 & Affirmative & 9 & Injury & 13 & Right & 13 \\
\hline Death & 14 & Covenant & 8 & Abused & 12 & Secure & 10 \\
\hline Unconstitutional & 11 & Effective & 8 & Failure & 12 & Refund & 9 \\
\hline
\end{tabular}




\section{Abortion Bills' Framing: Context(s)}

The broader historic, ideological, and political contexts surrounding the crafting and enactment of the abortion bills we examined lend further weight to the importance of our findings. Depicting these complex contexts is beyond the scope of this article, but it is important to acknowledge, even if briefly, how the bills in our sample aligned with either ProChoice or Pro-Life ideologies and how their skewed wording might lead to the "framing effect" described by Chong and Druckman (2007) - in other words, "how frames in the communications of elites (e.g., politicians, media outlets, interest groups) influence citizens' frames and attitudes" ( $p$. 109).

Restrictive Bills Since the appointment of Justices Brett Kavanaugh and Amy Coney Barret, numerous states including Texas, Missouri, and Mississippi enacted the most restrictive measures against abortion since Roe v. Wade was upheld by SCOTUS in 1973. Recurring examples of these restrictions include (but are not limited to) second trimester abortion bans, Targeted Regulation of Abortion Providers (TRAP) laws, and fetal heartbeat laws that would effectively criminalize abortion after six weeks' gestation.

Various scholars contend that purposeful imposition of barriers to abortion access is part of a "...national push for Pro-Life legislation" (Knopp, 2013, p.253), to "chip away at [the legality] of Roe v. Wade" (Dias \& Williams, 2019, Section A., p.14). Authors of lay-press articles also argue the increase in restrictive legislation is not coincidental, but intentional - to capitalize on an ideologically imbalanced Supreme Court and on the strong probability Roe v. Wade will be challenged in the court system in the near future.

Our findings regarding restrictive bills revealed frequent use of "Anti-Roe"/anti-abortion language, which negatively skewed the majority of their sentiment analysis scores. However, beyond the mere presence of "negative language," the manner in which the language is contextualized reinforces their alignment with political ideologies. As one example, abortion is rarely defined/described in clinical terms. Utah's HB136 described abortion as, "the intentional killing or attempted killing of a live unborn child through a medical procedure..." Indiana's HB1211, which bans second trimester abortion, explains the procedure as fetal dismemberment, i.e., when a "fetus is extracted...through clamps...or [any] instrument that...slices, crushes, or grasps a portion of the fetus' body to cut or rip it off." Another example is how some of the bills' language contextualizes abortion rates in the USA. Alabama's HB314 refers to the US abortion rate as "more than three times [those] killed in German death camps, Chinese purges, Stalin's gulags, Cambodia killing fields, and Rwandan genocide, combined."
The phrases outlined above appeal to gruesome, visceral images, which cannot avoid engaging readers' emotions and evoking strong affective reactions. It is difficult to dismiss such language/word choices as oversight by the bills' authors. Rather, the phrasing and writing style point to broader rhetorical strategies: first to highlight how abortion has disproportionately affected the "unborn," and second to create a sense of urgency regarding their "murder."

An additional contextual feature lending support to the alignment of the bills with political ideology is the notable absence of language addressing the people who seek abortions. Rather, almost unilaterally, the foci of these bills are the fetuses. Unsurprisingly, these rhetorical devices, namely, to prioritize fetal life over pregnant people's lives, align seamlessly with Pro-Life ideology. For example, the National Right to Life Committee's (NRLC) (the largest and oldest Pro-Life group in the US) mission statement contends, in part, their organization " .... is working to restore legal protection to the most defenseless members of our society who are threatened by abortion, infanticide, assisted suicide and euthanasia" (About NRLC I National Right to Life, 2021).

Protective Bills Alongside the enactment of some of the most restrictive measures against abortion since Roe $v$. Wade, the year 2019 also witnessed an outpouring of abortion-protective legislation. Many consider this body of laws as attempts to create state-wide protections in anticipation of Roe v. Wade's hypothetical revocation (Nash, 2019). Indeed, in the event Roe v. Wade is overturned by the Supreme Court, abortion legality will depend entirely on policy measures imposed by each state.

Much of the language in the protective bills overlaps with and points to Pro-Choice framing - an ideology that seeks to uphold pregnant people's right to make reproductive choices affecting their lives. As an example, the National Abortion Rights Action League (NARAL) Pro-Choice America's mission is worded as to "support and protect, as a fundamental right and value, a woman's freedom to make personal decisions regarding....reproductive choice" (NARAL Pro-Choice America Foundation, 2012). Protective bills framed abortion more often as an autonomous right and an inextricable component of reproductive healthcare access, both of which demand safeguarding. As with the wording of the restrictive bills, word choices framing protective legislation seem to be just as carefully and strategically selected to conform to a broader political rhetoric. For example, Vermont's HB57 bill defines abortion as: "the fundamental right of every individual who becomes pregnant to choose to carry a pregnancy to term, to give birth to a child, or to have an abortion." Illinois' SB25 frames abortion using similar language: “...the fundamental right of an individual who becomes pregnant to continue the pregnancy and give birth to a child, or to have 
an abortion, and to make autonomous decisions about how to exercise that right."

These claims stand in contrast to those in the restrictive bills, where abortion was defined and framed as a murderous act against an unborn person. Protective laws frame abortion as an autonomous choice whether to continue or terminate a pregnancy. Absent from the contextual language are the visceral terms and upward comparisons of abortion to genocide and the Holocaust, or other language that would otherwise inflate a negative sentiment score. In place of visceral language, we observe strong wording about consequences should personal rights be infringed. By framing the matter as a personal choice, the language emphasizes the role and rights of pregnant people and prioritizes them over their fetuses. It is important to note, nonetheless, that even though protective bills sometimes refer to fetuses as "children," they are not the unequivocal focus of these bills.

Among our findings it was intriguing to observe that negative sentiment is present among the protective laws, also: three bills exhibit overall negative scores comparable to, or even more negative than some of the restrictive bills (Illinois SB25, New York S2796, and Rhode Island H5125 had sentiment scores of $-175,-70$, and -85 , respectively). Upon closer examination of these scores' context, we found that these negative scores may partially stem from legal jargon (equally present in restrictive laws) that inherently carries a negative connotation. For example, New York's S2796 bill, which substantively revises that state's reproductive health infrastructure, outlines numerous sanctions and negative outcomes should legal rights to an abortion be infringed.

This finding (that some protective bills also scored negatively in the SA) points to an important feature when using SA as an analytical tool: taking into consideration the textual and political/historical contexts of the data/corpus being analyzed is essential for valid interpretation of findings. This feature notwithstanding, SA, remains a useful tool to identify and distinguish legal language characterizing polarized speech.

Impartially Written Bills Because NLP is the automated analysis of words, most studies rely on a neutral reference point (or null-model) to ground findings (see Bollen et al., 2021, for an example). For our study, we chose the US Constitution, which received a sentiment score of 1 , as reference given that this document serves as the legal backbone of the US government. It is worthy of notice that the Constitution's SA score was not 0 but biased towards a positive sentiment (although that bias is quantitatively small).

Compared to the Constitution's SA score, the protective and restrictive bills in our sample departed from neutrality to varying degrees. Two bills in our sample scored 0 , indicating a balance between positive and negative sentiment, or perfect neutrality. What is particularly intriguing is that each bill belongs to a different category: Georgia's HB481 outlaws abortion after a fetal heartbeat is detected; Vermont's $\mathrm{H} 57$ protects the right to choose or forgo contraceptive care and to continue or terminate a pregnancy. Absent from either law are polarized words that would otherwise alter sentiment scores - a particularly surprising feat considering some observers deemed Georgia's HB481 to be the second most restrictive abortion law in the US, at the time (Prabhu, 2021).

This finding suggests bills about controversial issues can, indeed, be neutrally worded, and avoid framing that appeals to positive or negative sentiments. Given that the US Constitution often serves as a model or reference for newly crafted legislation, perhaps the almost-neutral sentiment framing of its text should also be emulated.

\section{Possible Outcomes of Semantically Framed Legislation}

Findings from our sentiment analysis compel us to ponder some of the potential outcomes from the polarized framing of abortion bills/laws. One outcome regards potential "framing effects": Because the wording of abortion-related legislation can shape or influence what the public believes, how lay people vote, and how legislators interpret these laws, it is reasonable to raise the issue of intent. Chong and Druckman (2007), for instance, claim that the careful selection of words to frame an issue is, more often than not, intentional. If the claim is valid, we cannot avoid inferring that each of the bills in our analyses was strategically worded to appeal to partisan preferences of a region or group(s) of people and intended to be interpreted in a manner consistent with these preferences (Oliver et al., 2019).

The effects of framing, however, are not limited to satisfying partisan preferences, but may also intend to influence the approval and enactment of the framed legislation. Although the SCOTUS, defined by the US Constitution as a separate, distinct, and impartial branch of government, evaluates laws by their constitutionality, Supreme Court Justices are not immune to partisan biases that affect how they interpret laws (Kang \& Shepherd, 2010). Indeed, justices are commonly branded with "liberal" or "conservative" labels and widely expected to rule on cases within the scope of their political ideology.

Within the last 3 years, the ideology of the Supreme Court has shifted to be the most conservative since 1950 - well before the modern Reproductive Rights movement of the 1960s and the landmark 1973 decision about abortion in Roe v. Wade. Therefore, questions and concerns about the future of Roe v. Wade, alongside the broader issue of reproductive rights, remain. Many of the bills included in our analyses are currently 
being challenged within the court system; and the Supreme Court will hear an abortion related case on Mississippi's challenged bill which bans abortions after roughly 15 weeks, among other restrictive measures.

We acknowledge that predicting how a strongly conservative SCOTUS may rule in the future, when handling legal challenges to abortion, Roe v. Wade, or reproductive care more broadly, remains sheer speculation. However, it bears repeating the obvious: bills/laws framed around a partisan issue are likely to be interpreted in a manner consistent with one's political ideology and legal paradigm. With the addition of Brett Kavanaugh (appointed in 2018) and Amy Coney Barrett (appointed in 2020), the majority of Supreme Court Justices currently serving on the bench are interpretivists. Legal Interpretivism is a paradigm in which laws are interpreted as written (Stavropoulos, 2021). Thus, should any of the abortion bills be challenged at the SCOTUS, Justices may be weighing the constitutionality of the laws entirely on facevalue interpretations of the laws' texts and their wording. If these judges are swayed by a Conservative leaning ideology, the framing of the bills may reinforce their beliefs and lead to the upholding of restrictive laws and/or to the banning of legal abortion services altogether. Thus, concerns about the constitutionality of these laws, and the future of Roe v. Wade, are not unfounded, given the sheer volume of proposed bills suffering from significant language biases, since 2019.

\section{Limitations}

Despite its contributions, this study is subject to limitations. First, hundreds of bills about abortion were motioned and enacted into law in 2019. However, our study specifically focused on 19 state bills, and their accompanying laws. These bills represented some of the most politicized protective/restrictive laws that were enacted into law that year. We acknowledge the inclusion of additional laws in the analysis would possibly yield more nuanced outcomes. Additionally, we acknowledge that more sophisticated sentiment analysis algorithms are available for use (i.e., the Valence Aware Dictionary and sEntiment [sic] Reasoner [VADER]) (Hutto \& Gilbert, 2014). Yet, tools such as VADER are used almost exclusively for more complicated data, including those derived from social media, as those algorithms are adjusted for vernacular and language inherent to online spaces. Thus, our use of a more conventional ratio-derived sentiment analysis algorithm, although lacking in sophistication, was appropriate for our text data comprising professionally written documents, not lay-language vernacular. Lastly, disparate sample sizes barred us from conducting formal tests of significant differences between restrictive and protective bills (but we do acknowledge these tests might not have added valuable information).

\section{Conclusion}

Sentiment analysis has been widely used to track lexical features of open-ended text data (Fang et al., 2016), but most applications of sentiment analysis focus on texts accessible through social media or other online outlets, rather than professional and/or legal texts (Cambria et al., 2013). Thus, we can conclude with reasonable confidence this study is the first to track lexical features and consider potential implications of abortion-focused bills/laws recently enacted in the USA. Beyond descriptive findings that highlight the propensity to use certain language based on ideological parameters, our findings point to significant implications of framing legal language and subsequent interpretations.

Lastly, we extend a call to researchers to further examine this topic. Studies that employ qualitative methods and analyses of legal texts are sorely needed. Cognitive interviews - a specific interviewing technique that elicits how people understand or internalize survey questions (Beatty \& Willis, 2007) - can identify how participants understand phraseology of protective and restrictive bills, leading to a better understanding of the effects of particular rhetoric on enacted legislation. Further studies of legal texts' language and wording, through SA or other NLP techniques, also should be added to the knowledge base, to inform both the lay public and legislators. Given increased political polarization in the USA (PEW Research Group, 2014), we can argue people will likely interpret laws in a manner consistent with their political ideologies. However, this argument remains speculative, given the paucity of empirical research on framing and on personal interpretations of framed legal texts.

Data Availability Upon acceptance, raw data will be deposited into a GitHub repository.

Code Availability Sentiment analysis code can be found at https://cran.rproject.org/web/packages/SentimentAnalysis/SentimentAnalysis.pdf. Code germane to the study will be made available in a GitHub repository.

\section{Declarations}

Conflict of Interest The authors declare no competing interests.

\section{References}

About NRLC I National Right to Life. (2021). Retrieved October 21, 2021, from https://www.nrlc.org/about/

Bathina, K. C., Ten Thij, M., Lorenzo-Luaces, L., Rutter, L. A., \& Bollen, J. (2021). Individuals with depression express more distorted thinking on social media. Nature Human Behaviour, 1-9 https://doi.org/ 10.1038/s41562-021-01050-7

Beatty, P. C., \& Willis, G. B. (2007). Research synthesis: The practice of cognitive interviewing. Public Opinion Quarterly, 71(2), 287-311. https://doi.org/10.1093/poq/nfm006 
Blei, D. M., Ng, A., \& Jordan, M. (2003). Latent Dirichlet allocation. Journal of Machine Learning Research, 3, 30.

Bollen, J., Ten Thij, M., Breithaupt, F., Barron, A. T. J., Rutter, L. A., Lorenzo-Luaces, L., \& Scheffer, M. (2021). Historical language records reveal a surge of cognitive distortions in recent decades. Proceedings of the National Academy of Sciences, 118(30). https://doi.org/10.1073/pnas.2102061118

Cambria, E., Schuller, B., Xia, Y., \& Havasi, C. (2013). New avenues in opinion mining and sentiment analysis. IEEE Intelligent Systems, 28(2), 15-21. https://doi.org/10.1109/MIS.2013.30

Cao, J., Zeng, K., Wang, H., Cheng, J., Qiao, F., Wen, D., \& Gao, Y. (2014). Web-based traffic sentiment analysis: Methods and applications. IEEE Transactions on Intelligent Transportation Systems, 15(2), 844-853. https://doi.org/10.1109/TITS.2013.2291241

Chong, D., \& Druckman, J. N. (2007). Framing theory. Annual Review of Political Science, 10(1), 103-126. https://doi.org/10.1146/annurev. polisci.10.072805.103054

Dias, E., \& Williams, T. (2019, February 8). Anti-abortion activists still see their best chance in years to chip away at Roe v. Wade. The New York Times. https://www.nytimes.com/2019/02/08/us/ anti-abortion-activists-roe-v-wade.html

Druckman, J. N. (2004). Priming the vote: Campaign effects in a U.S. Senate election. Political Psychology, 25(4), 577-594. https://doi. org/10.1111/j.1467-9221.2004.00388.x

Fang, R., Pouyanfar, S., Yang, Y., Chen, S.-C., \& Iyengar, S. S. (2016). Computational health informatics in the Big Data age: A survey. ACM Computing Surveys, 49(1), 12:1-12:36. https://doi.org/10. $1145 / 2932707$

Feick, L., Donnay, K., \& McCabe, K. T. (2021). The subconscious effect of subtle media bias on perceptions of terrorism. American Politics Research, 49(3), 313-318. https://doi.org/10.1177/1532673X20972105

Feldman, R. (2013). Techniques and applications for sentiment analysis. Techniques and Applications for Sentiment Analysis, 56(4), 82-89.

Gambrill, E., \& Reiman, A. (2011). A propaganda index for reviewing problem framing in articles and manuscripts: An exploratory study. PLoS One, 6(5), e19516. https://doi.org/10.1371/journal. pone.0019516

Gibson, J. L., \& Nelson, M. J. (2014). The legitimacy of the US Supreme Court: Conventional wisdoms and recent challenges thereto. Annual Review of Law and Social Science, 10(1), 201219. https://doi.org/10.1146/annurev-lawsocsci-110413-030546

Hutto, C., \& Gilbert, E. (2014). VADER: A parsimonious rule-based model for sentiment analysis of social media text. Proceedings of the International AAAI Conference on Web and Social Media, 8(1), Article 1. https://ojs.aaai.org/index.php/ICWSM/article/ view/14550

Kang, M. S., \& Shepherd, J. (2010). The partisan price of justice: An empirical analysis of campaign contributions and judicial decisions [SSRN Scholarly Paper]. Social Science Research Network. https://papers.ssrn.com/abstract $=1649402$

Knopp, J. L. (2013). The unconstitutionality of Ohio's House Bill 125: The Heartbeat Bill. Akron Law Review, 46, 35.

Kotsiantis, S. B. (2007). Supervised machine learning: A review of classification techniques. 20.
Lehr, D., \& Ohm, P. (2017). Playing with the Data: What Legal Scholars Should Learn about Machine Learning., 51, 65.

Litman, L. (2020). Redefifining reproductive rights and justice. Michigan Law Review. https://doi.org/10.3316/agispt.20200527030916

McKeegan, M. (1993). The politics of abortion: A historical perspective. Women's health issues: official publication of the Jacobs Institute of Women's Health, 3(3), 127-131.

Mukherjee, S., \& Bhattacharyya, P. (2012). Feature specific sentiment analysis for product reviews. In A. Gelbukh (Ed.), Computational linguistics and intelligent text processing, 7181, 475-487. Springer Berlin Heidelberg. https://doi.org/10.1007/978-3-64228604-9_39

NARAL Pro-Choice America Foundation. (2012, February 21). America's charities. https://www.charities.org/charities/naralpro-choice-america-foundation

Nash, E. (2019). Abortion rights in peril-What clinicians need to know. New England Journal of Medicine, 381(6), 497-499. https://doi.org/10.1056/NEJMp1906972

Oliver, M. B., Raney, A. A., \& Bryant, J. (Eds.). (2019). Media effects (Fourth edition). Routledge.

PEW Research Group, \& Inquiries. (2014). Political polarization in the American public. Pew Research Center - U.S. Politics \& Policy. https://www.pewresearch.org/politics/2014/06/12/politicalpolarization-in-the-american-public/

Pozen, D. E., Talley, E. L., \& Nyarko, J. (2019). A computational analysis of constitutional polarization. Cornell Law Review, 105, 85.

Prabhu, M. T. (2021). Georgia anti-abortion law heads back to court in September. The Atlanta Journal-Constitution.

Procellochs, N., \& Feuerriegel. (2021). "SentimentAnalysis version 1.3-4" CRAN archive information. Retrieved October 21, 2021, from https://cran.r-project.org/web/packages/SentimentAnalysis/ SentimentAnalysis.pdf

Stavropoulos, N. (2021). Legal interpretivism. In E. N. Zalta (Ed.), The Stanford Encyclopedia of Philosophy (Spring 2021). Metaphysics Research Lab, Stanford University. https://plato.stanford.edu/ archives/spr2021/entries/law-interpretivist/

Tannen, D. (1993). Framing in Discourse. Oxford University Press.

Valdez, D., \& Goodson, P. (2020). Language bias in health research: External factors that influence latent language patterns. Frontiers in Research Metrics and Analytics, 5, 4. https://doi.org/10.3389/ frma.2020.00004

Valdez, D., Picket, A. C., Young, B.-R., \& Golden, S. (2021). On mining words: The utility of topic models in health education research and practice. Health Promotion Practice, 22(3), 309-312. https:// doi.org/10.1177/1524839921999050

Valdez, D., Ten Thij, M., Bathina, K., Rutter, L. A., \& Bollen, J. (2020). Social media insights Into US mental health during the COVID-19 pandemic: Longitudinal analysis of Twitter data. Journal of Medical Internet Research, 22(12), e21418. https://doi.org/ $10.2196 / 21418$

Publisher's Note Springer Nature remains neutral with regard to jurisdictional claims in published maps and institutional affiliations. 